\title{
The concept of Culture in Critical Mathematics Education
}

Brendan Larvor (phlqbpl@herts.ac.uk) University of Hertfordshire, Hatfield, England Karen François (karen.francois@vub.ac.be) Center for Logic and Philosophy of Science, Free University Brussels (VUB)

Abstract:

A well-known critique in the research literature of critical mathematics education suggests that framing educational questions in cultural terms can encourage ethniccultural essentialism, obscure conflicts within cultures and promote an ethnographic or anthropological stance towards learners.

Nevertheless, we believe that some of the obstacles to learning mathematics are cultural. 'Stereotype threat', for example, has a basis in culture. Consequently, the aims of critical mathematics education cannot be seriously pursued without including a cultural approach in educational research.

We argue that an adequate conception of culture is available and should include normative/descriptive and material/ideal dyads as dialectical moments.

\section{Ethnomathematics and its discontents}

The concept of culture is rarely invoked explicitly in the research literature on critical mathematics education. The reason for this is not hard to find. Ole Skovsmose, the founding father of critical mathematics education, was deeply affected by the apartheid system in South Africa (Skovsmose first arrived in South Africa in 1993 and later started to collaborate with the South African researcher Renuka Vithal). Consequently, he is very careful in his use of the notion of culture. A so-called 'appreciation' of pupils' cultural background (such as Zulu culture) could be associated with people "out there" and "down there" (Skovsmose 2014: 64). Cultural approaches run the risk of essentialism and worse. For Skovsmose, the fact that pupils have cultural backgrounds is not a "simple truth" (Skovsmose 2014: 64).

Meanwhile, in the literature on mathematics education, 'culture' has become associated with the ethnomathematics movement, because the ethnoi of ethnomathematics are "identifiable cultural groups". ${ }^{1}$ Thus, 'culture' (at least when used as a count-noun) is part of the founding definition of ethnomathematics. This movement was the object of a withering critique from the critical mathematics education research group by Skovsmose and Vithal (1997). The principal point of this critique was that the ethnomathematical approach is uncritical with respect to the cultures that pupils belong to, the discourses around culture in general and the role of mathematics in formatting the world as we experience it. Regarding the cultural backgrounds of pupils, Skovsmose and Vithal argue that these might not be entirely benign or free from internal conflict. Indeed, it would be a very unusual human culture that had no internal conflicts, egregious power

\footnotetext{
${ }^{1}$ D’Ambrosio (1985) p. 45.
} 
relations or structural injustices. Turning to the broader discourse, talk about 'culture' can easily fall into a reductive ethnic essentialism and even outright racism. They make this point dramatically by shifting the context of the discussion from Brazil (where ethnomathematics emerged) to South Africa. They argue that, in that context, the proposal that pupils from different ethno-cultural backgrounds should have different kinds of mathematical education to reflect their cultural differences sounds rather like the rationale that used to be given for the educational arrangements under apartheid.

Skovsmose and Vithal do not suggest that the ethnomathematics movement is somehow guilty of implicit racism or secretly supportive of apartheid. On the contrary, they affirm that they share the progressive goals of the ethnomathematics movement. Rather, their point is that the ethnomathematics research programme lacks the theoretical resources to distance itself from apartheid education. In his programmatic works on ethnomathematics, D'Ambrosio took a broad view of his core notion, thus, "we will call ethnomathematics the mathematics which is practised among identifiable cultural groups, such as national-tribal societies, labor groups, children of a certain age bracket, professional classes, and so on." (1985:45). The ethnoi of his ethnomathematics are not solely racial or national-tribal groups. But they do include nationaltribal groups, and this makes it difficult to explain in technical, scientific, value-neutral terms why the proponents of apartheid education should not be part of the ethnomathematics movement. The reason they cannot join is that the apartheid regime and the ethnomathematics movement have quite different political goals, but this reference to political goals cannot be part of the technical core of a scientific research programme.

In general, the ethnoi of D'Ambrosio's ethnomathematics are groups to which learners are assumed to belong simply and unproblematically. Part of Skovsmose and Vithal's argument is that membership of such groups is often involuntary and may be established, achieved or imposed through the exercise of power-relations. Discovering mathematics in the practices of a group to which one is proud and glad to belong is one thing. It is another to have one's mathematics education tangled up with a group-membership that is uneasy or coerced, or which one is unwilling to discuss in class. Above all, ethnomathematics addresses the learner as a member of a cultural group, rather than as an individual. Of course, it does not follow that teachers who bring an ethnomathematical approach into their pedagogy must be guilty of treating their pupils as instances of types. This is unlikely to happen. The point rather is that ethnomathematics as pedagogical theory has no resources to explain why they should not treat pupils solely as instances of their ethnic types. For example, Presmeg (1998), working in the USA, identifies four principles for introducing ethno-cultural material into school mathematics classes. The first two are:

1. Each student is considered as having a unique sociocultural history; each student has ethnicity. 
2. This ethnicity is a mathematical resource; mathematics may be developed from associated cultural practices. ${ }^{2}$

The first principle is a clear expression of the conflict between treating learners as individuals and treating them as members of cultural groups. Each student does indeed have a unique sociocultural history - that is part of what makes each student a unique individual, not reducible to membership of any group. It is also the case that each student has ethnicity, that is, belongs to some cultural group(s). But the second of these truths cannot possibly be an explication of the first. This is because membership of such groups is not a simple, unproblematic relation that we might symbolise thus: $x \in A$. Rather, belonging to a group is a task-one has to work out what it means for oneself to be female, or Irish, or heterosexual, or black, or the child of immigrants or market traders, or whatever it might be. Each person might carry out these tasks differently. Each of us might come to a different accommodation with membership of whichever groups we happen to find ourselves in. In other words, it's not quite right to say that "each student has ethnicity", as each student has a blood group and a shoe size. Rather, each student constructs (or struggles with) his or her ethnicities. Ethnicity is not a fixed property but a dynamic process of giving meaning to the different constituents of identity. This too is part of our individuality.

This is not Presmeg's confusion alone-it arises from the combination of an ethnomathematical approach and a proper concern for individual difference. The second principle states starkly that the learners' ethnicities are a resource for the teacher (who may belong to some other ethnicity altogether) to use in the teaching of the school curriculum. Learners are likely to notice when their cultures are being instrumentalised. They may resent it, and they could not be blamed if they did. Here again, we cite Presmeg only because she expresses the logic of ethnomathematical pedagogy with unusual clarity, and thereby displays its aporia.

Ethnomathematics suffers from some other logical tensions that will have a bearing on the present argument. It pretends to treat all mathematical practices equally, but it a) seeks to valorise some practices and denigrate some forms of education and b) imposes the concept of mathematics on practices found in cultures where this concept is not present-specifically, a concept of mathematics that is abstract and modern (dating from the early twentieth century). Until relatively recently, European mathematicians understood mathematics to be the science of number, magnitude and geometrical space. This was Kant's (1724-1804) view; his philosophical account of mathematical knowledge founded it on arithmetic and geometry (each in turn grounded in a suitable pure intuition). ${ }^{3}$ When his near contemporary Euler (1707-1783) received the Königsberg bridges problem, he wrote in reply, “...this type of solution bears little relationship to mathematics, and I do not understand why you expect a mathematician to produce it, rather than anyone else, for the solution is based on reason alone, and its discovery does not depend on

\footnotetext{
2 Presmeg (1998) p. 321

${ }^{3}$ Critique of Pure Reason. The details do not matter for the present purpose-all we need is that for Kant, if you have arithmetic and geometry, you have mathematics.
} 
any mathematical principle. ${ }^{\prime 4}$ We now recognise the Königsberg bridges problem as belonging to mathematics, specifically, to graph theory. In order to see the mathematics in basket-weaving, string forms, kolam-drawing and city tour-route design, it is necessary to move beyond the antique conceptions of Euler and Kant, and to deploy an up-to-date notion of mathematics such as "the science of patterns" or "the science of detachable relational insights" 5 . Such broad definitions reflect the rise in the twentieth century of mathematics concerned with such abstracta as sets, graphs, topologies, morphisms and categories. (For the argument that twentieth-century academic mathematics marks a deep shift from its precursors, see Lautman 2006 or Gray 2008.) In other words, ethnomathematics breaks the first rule of anthropology in spectacular fashion. It analyses 'ethnic' practices using a concept imposed from without, a concept, moreover, which is only intelligible to the relatively small number of people with a university-level education in contemporary pure mathematics.

Aside from this spectacular violation of anthropological method, the appeal to this modern, abstract notion of mathematics presents a practical pedagogical difficulty. One way of using ethnomathematics in the classroom is to offer pupils activities that can function as a bridge from the mathematical practices they already engage in to the school mathematics curriculum and thence to practical mathematics for their future lives. This may be plausible if the pupils' mathematical practices are relatively close to the curriculum-for example, if they are already using money or weights and measures. However, ethnomathematics tends to elide mathematical practices with practices susceptible of mathematical analysis. As Presmeg reports, “Millroy's... carpenters, Saxe's... candy sellers, Lave's... grocery shoppers - none of these considered themselves to be engaged in doing mathematics." (Presmeg 1998:328). She goes on to make the point vivid with a study that finds a dihedral group of order eight in the Warlpiri kinship system. We might persuade people that measuring and counting wood, candy, groceries and money are examples of the same activity as school mathematics. We are unlikely to persuade the Warlpiri that in forming marriages, they're doing algebra. Similarly, there is in print a mathematical analysis of tying a neck-tie (which activity is, from a mathematical point of view, equivalent to a short walk on a triangular lattice). ${ }^{6}$ No-one supposes that tying a neck-tie is a mathematical practice, even though it consists of iterations of elementary operations. Certainly, the authors did not take themselves to be writing ethnomathematics. Activities such as tie-tying and basket-weaving only count as mathematics because modern mathematicians can recognise abstract structures in them, but this is unlikely to help learners. If the path from ethnomathematical practices to book-keeping, engineering and statistical analysis has to go through group theory or graph theory, it is unlikely to

\footnotetext{
${ }^{4}$ Leonhard Euler, letter of April 1736, quoted in Hopkins \& Wilson (2004) p. 201. He went on to complicate this point by wondering whether the bridge-problem might be the sort of thing that Leibniz had gestured at with his talk of 'geometry of position'. Nevertheless, the example stands up well enough for the present purpose.

${ }^{5}$ Thomas (1996) and Steen (1990) respectively, both quoted in Presmeg (1998) p. 328.

${ }^{6}$ Fink \& Mao (2001)
} 
offer much improvement on existing routes. Pupils might do better starting school mathematics from a blank slate after all.

In their analysis, Vithal \& Skovsmose (1997) drew on some of Pierre Bourdieu's ideas on the reproduction of the social structure and the mediating role of the school. They argue that identifications of students aligned with cultural categories (class, race, gender, ...) establish expectations regarding their academic success. These expectations may suppress or repress the student's academic performances, both predicted and recorded (since the former influences the latter). This role of the school system in reproducing social structure is rarely discussed (Bourdieu 1996). Vithal \& Skovsmose (1997) introduce their notion of foreground, which they understand as 'the set of opportunities that the learner's social context makes accessible to the learner to perceive as his or her possibilities for the future' (Vithal \& Skovsmose 1997: 147). Skovsmose emphasises the political and cultural situation as an important aspect of the foreground since they condition the opportunities for the learner (Skovsmose, 2005). The notion of foreground also makes the political nature of the learning process explicit. From this context we can understand that Skovsmose gives more attention to the notions of politics and sociology-rather than the concept of culture-to analyse educational processes in contemporary societies (Alrø, Ravn \& Valero 2010).

Skovsmose's work deeply influenced research in critical mathematics education and increased the focus on the micro-level of mathematics education. The notion of culture within the research community of critical mathematics education almost disappeared, as may be seen in the festschrift for Ole Skovsmose (Alrø et al. 2010). The preface indicates that Skovsmose's work mostly contributed to mathematics (education) in relation "to society, educational thinking that emphasises the politics and sociology of educational processes in mathematics, and pedagogical thinking that connects the philosophical and educational reflections with issues of relevance for the micro-processes of teaching and learning of mathematics" (Alrø et al. 2010: vii).

Note that Skovsmose and Vithal direct their critique principally at ethnomathematics as a pedagogical proposal (p. 135). They do not oppose the project of investigating ethnic practices that fall under the broadest possible conception of mathematics, broadening the history of mathematics or examining mathematics in non-academic contexts. The debate has evolved since 1997-see Pais (2010) for a summary of developments after Skovsmose and Vithal's critique, Skovsmose (2011:84-87 and 2015) for a recent statement of his reservations about ethnomathematics as pedagogy, and Knijnik (2012) for an attempt to make good the shortcomings of ethnomathematical theory. None of the points in this section is original-they all occur in the cited literature. The purpose of this first section is just to explain why people in the critical mathematics education research group rarely deploy 'culture' as a technical term, even if they sometimes use the word. 


\section{Culture, again}

One of the claims of this paper is that the concept of culture is important for understanding mathematical practices and mathematics education. Having sketched some of the problems arising from the word's association with ethnomathematics, we are in a position to ask whether it is possible to recover a concept of culture that can escape these difficulties. To that end, this section will develop a reflection on the notion of culture in general. It draws on arguments elaborated in Larvor (2016a).

The word 'culture' is semantically rich. Its many meanings divide into two broad groups: normative/educative and descriptive/scientific. On one side, there are the normative senses in which culture is a good thing, valuable in its own right and for the people who have it, both individually and collectively. Thus, a person may be cultured. Such use of the term 'culture' requires a high level of confidence in the associated evaluations. One must firmly believe that one knows what is valuable in order to deploy the word in this way, and be confident of culture's good effects. Culture, thus understood, stands in contrast to nature and ennobles the youth fortunate to be educated in it. Culture in this sense need not be 'high culture', that is, great works of high art, but it does require distinctions of quality and some sense of sustained tradition. Even the most recently emerged genres of art and music have agreed masterpieces and landmarks. Any aspiring rappers now must know their Public Enemy from their Run DMC. Mathematics can constitute culture in this sense-one reason for keeping it in the curriculum is that it is part of the common cultural treasury of humanity. Paul Ernest, speaking at a conference in London on mathematical cultures, spoke of introducing learners to the 'poetry of mathematics'. ${ }^{7}$ We may wonder-without cynicism-whether it would be possible to justify the teaching of mathematics on the same grounds as the teaching of poetry. ${ }^{8}$ Notice that in this paragraph, 'culture' functions as a massnoun.

This family of normative/educative senses of 'culture' forms a dyad with the family of descriptive/scientific senses. We say 'dyad' because every distinction establishes a relation, and traces of the normative/educative sense are detectable throughout the descriptive and scientific literature on culture in general and mathematical cultures in particular. In any case, we should expect to see a normativity implicit in any research directed at the question 'How can we teach mathematic better', even if that research makes explicit use of descriptive or scientific concepts of culture. Indeed, Skovsmose (without mentioning culture) explicitly refers to this interplay between the normative and descriptive aspects of critical mathematics education. ${ }^{9}$ We therefore think that

\footnotetext{
${ }^{7}$ https://sites.google.com/site/mathematicalcultures/

8 There is, for example, more than a trace of Matthew Arnold in Paul Lockhart's (2009). Ernest (2000) makes a distinction between capability and appreciation that emphasises the value of mathematics as cultural achievement. ${ }^{9}$ See the interview in Alrø, Ravn and Valero (2010) pp. 1-9, in which he relates his thinking to philosophers associated with critical theory such as Habermas, Adorno and Foucault. Especially: "A critical activity cannot only represent
} 
the normative/educative and the descriptive/scientific senses of 'culture' stand in dialectical relation rather than absolute separation.

On the descriptive, scientific or anthropological senses of the term 'culture', a good place to start is the magisterial literature review in Kroeber, A.L., \& Kluckhohn, C. (1952) Culture: A critical review of concepts and definitions. This report starts with the first recorded scholarly uses of the term and tracks its evolution and differentiation up to their time of writing. This is of some interest, given the discussion so far, because Kroeber and Kluckhohn explore both sides of the descriptive/normative distinction, and their historical survey includes those German thinkers of the nineteenth century who saw this distinction as the ground of a relation.

At the end of their historical journey, Kroeber and Kluckhohn land on this definition of culture, which they take to be an approximation of the view of "most social scientists":

Culture consists of patterns, explicit and implicit, of and for behavior acquired and transmitted by symbols, constituting the distinctive achievements of human groups, including their embodiments in artifacts; the essential core of culture consists of traditional (i.e. historically derived and selected) ideas and especially their attached values; culture systems may, on the one hand, be considered as products of action, and on the other as conditioning elements of further action. ${ }^{10}$

In this definition, we see a tension that turns up more widely in the descriptive senses of culture. The first part of this definition presents culture as patterns of behaviour, embodied in and transmitted by symbols and artefacts. From a positivist or behaviourist point of view, that sounds scientifically respectable. Symbols, artefacts and behaviours are all empirically detectable (setting aside the question of how a purely empirical consciousness could recognise them as symbols, artefacts and behaviours). However, they go on to say that the core of (a) culture is "ideas and especially their attached values". Ideas and values are not so easy to detect empirically, except perhaps indirectly through their effects. This mention of values is not an afterthought; on the contrary, for Kroeber and Kluckhohn, values are central to anthropology: "Values provide the only basis for the fully intelligible comprehension of culture, because the actual organisation of all cultures is primarily in terms of their values." 11 It is also worth noting their use of the term 'achievement'. This is a success-word, and therefore invokes a normative sense of culture, though presumably the criteria of success are culture-specific.

Social science has not stood still since 1952, but the core of Kroeber \& Kluckhohn's account is recognisable in more recent definitions of culture. Writing in 1989, Banks, Banks, \& McGee claim that,

uncertainty. It also represents concerns, and the formulation of concerns immediately brings us to the formulation of visions, aspirations, and hopes." (p. 7).

${ }^{10}$ Kroeber \& Kluckhohn 1952 p. 181

${ }^{11}$ Kroeber \& Kluckhohn 1952 p. 340. Note that 'culture' occurs in this sentence both as a mass-noun and as a countnoun. 
Most social scientists today view culture as consisting primarily of the symbolic, ideational, and intangible aspects of human societies. The essence of a culture is not its artifacts, tools, or other tangible cultural elements but how the members of the group interpret, use, and perceive them. It is the values, symbols, interpretations, and perspectives that distinguish one people from another in modernized societies; it is not material objects and other tangible aspects of human societies. People within a culture usually interpret the meaning of symbols, artifacts, and behaviors in the same or in similar ways. ${ }^{12}$

We should expect to find this taut duality in any study of culture because the two ends need each other. The behaviours and artefacts do not classify themselves or explain themselves; the ideas and values must body forth in words, deeds and things if they are to have any presence at all. We can find this tension in the philosophy of mathematical practice. Mathematics is obviously concerned with ideas, but studying mathematical practices directs attention to artefacts (blackboards, notations, diagrams, models and computers) and behaviours (gesticulating, writing, sketching, gathering mathematicians in groups of various sizes, etc.).

Kroeber and Kluckhohn's emphasis on values as "the only basis for the fully intelligible comprehension of culture" conforms to some popular usages, especially when culture is contested. 'Cultural issues' in politics are precisely those that are not driven primarily by prudence or efficiency, and they tend to form blocs-support for rote-learning of times-tables tends (in the UK at least) to coincide with social conservatism and a yearning for deference, while enthusiasm for whole-book teaching of reading sits with environmentalism and new-age spirituality. These blocs do not make sense in practical terms - there is no logical reason why a person's view about teaching basic literacy or numeracy should predict their foreign policy stances or their openness to religious innovation. Rather, these apparently technical judgments (such as, how best to teach multiplication or the extent of human influence on the global climate) come to seem expressive of some general values and attitudes towards authority, society and the self. That is what expressions like 'culture wars' seek to capture. Similarly, there is a whole industry dedicated to achieving cultural changes in organisations, as managements have come to believe that changing policies and practices alone do not achieve their desired ends. In December 2015, there was a scandal because the UK Financial Conduct Authority dropped its report into banking culture. The suspicion fuelling the sense of scandal was that political pressure was brought to bear precisely because a review that addressed the culture of banking might achieve changes that piecemeal adjustments to rules and practices cannot.

This rather abstract discussion then gives us two thoughts:

12 Banks, J.A., Banks, \& McGee, C. A. (1989). Note the reference to 'modernized societies'. 
1. There is a dialectical relationship between the material aspects of culture (the artefacts and practices) and the ideas and values, such that culture is unintelligible without reference to values.

2. There is a relation between descriptive and normative approaches to culture such that the normative aspect can never be eliminated. To understand a culture is to understand its values, but this always involves some dialogue with the researcher's own values (even if these are solely norms of scientific practice).

\section{The Interest of Mathematics Education in Culture}

Our emphasis on the centrality of values for the intelligibility of culture has consequences for both approaches to mathematics education under discussion here. For ethnomathematics, the ethnoi are defined culturally, which on our view means, through their values. Thus teachers who instrumentalise ethnic practices for mathematics teaching bring value-laden practices into the classroom without knowing what those values are-nor how they will stand in relation to the values of the individual students, the classroom, the school and the curriculum. ${ }^{13}$ So, our claim that cultures must be understood in terms of their values clarifies and deepens the existing critique of ethnomathatical pedagogy. On the other hand, this same claim of ours supports D'Ambrosio's insistence that all groups are socioculturally determined, including Western academic mathematicians. Bishop $(2008,2016)$ identified and analysed values connected to Western academic mathematics (see also Ernest 2016). If Kroeber and Kluckhohn are right that the core of a culture is its values, then Bishop's work shows us the core of the culture of Western mathematics. Our development of the notion of culture articulates more clearly the ethnomathematicians' claim that the Western mathematics curriculum also brings value-laden practices into the classroom. It remains to be seen what effect this might have on the grander aspirations of the ethnomathematics movement, which are to build a civilization that rejects the colonial politics of imposing one curriculum (the Western one) worldwide (Pinxten \& François 2011). They hope to restore cultural dignity, reinforce cultural self-respect and empower currently excluded people and societies (D'Ambrosio 2015). Nevertheless, articulating these aims in terms of values (which can overlap and inform each other) rather than discrete cultures might offer more practical possibilities than does the simple narrative of oppression and resistance.

Our development of the notion of culture may have another consequence for the ethnomathematics programme. Our suggestion that descriptive and normative aspects of culture cannot be wholly separated entails that wholly value-neutral anthropology is impossible. This may offer researchers in ethnomathematics a defence against the charge that their work is too interested in pedagogy and politics to count as science. If we are right, then all ethnology is an

\footnotetext{
${ }^{13}$ For analyses of national differences in school and classroom cultures, see essays by Andrews and Gosztonyi in Larvor (2016b).
} 
encounter between value-imbued research practices and value-imbued 'ethnic' practices. Then the question is not, how can this encounter be rendered value-free, but rather, how can it be negotiated?

Turning to critical mathematics education, recall Kroeber and Kluckhohn's claim that culture systems are "conditioning elements of further action". In other words, pupils' background and foreground (in Skovsmose's sense) are determined in part by culture. Culture tells you what is possible and what is worth doing, and it tells you where you fit in. Skovsmose and Vithal developed the notion of foreground precisely to criticize and to overcome the stereotyping effects of pupils' backgrounds. Stereotyping affects the recorded and expected performances of pupils and therefore it affects their futures. The notion of foreground is developed to make learning obstacles visible as political issues based on the students' backgrounds rather than as individual phenomena. The notion of foreground frames the teaching and the learning of mathematics within a social and political context of 'social justice education' in order to overcome cultural determination (Burton 2003, François 2016). Although the notion of foreground and the programme of social justice are part of culture, critical mathematics researchers emphasise more the social and political aspect due to the association of culture with determinism, as we discussed in the first section. We argue that this is a missed opportunity, because an appropriate notion of culture can forge analytic connections between ethnomathematics, critical mathematics education and work on values in mathematics by Bishop and Ernest.

One example-omnipresent in the social justice debate-is the gendering of mathematics, particularly the widespread conviction that it is not for girls. This shows itself to some degree in measurable effects such as stereotype threat. ${ }^{14}$ This is the reduction in cognitive test performance caused by reminding subjects that they are members of groups that are stereotypically less good at tasks of the type tested. For example, the reminder might take the form of requiring subjects to write their genders on the front of their answer-books. There is a measurable effect in the case of mathematics, though this varies with age and with the degree of commitment to mathematics. One might think that the solution is to avoid such reminders, both in the testing procedure (use of candidate numbers rather than names, for example) and in the test content. However, experiments on stereotype threat do not record all the effects of sexist culture. They merely record the effect of a reminder of group membership on the day of the test. Girls going in to a mathematics exam already know that they are girls, even before they write ' $F$ ' in a box on the front of their answer-book or fill in their gendered names. The experiments on stereotype threat do not capture the effects of this prior knowledge on their learning. Nor do they measure the effects of gendered stereotypes on girls' choices-we do not know how many girls choose not to study mathematics as a result of their being persuaded that it is not for them. What the stereotype threat experiments do suggest is that these effects may be significant.

\footnotetext{
${ }^{14}$ See Doyle \& Voyer (2016)
} 
In general, sexism, racism, class-prejudice, etc. are cultural (that is, value-laden) structures that may find expression in all sorts of practices - this is the material-ideal dyad in action. If we think about practices in isolation without considering that they are expressive of and ramifying of clusters of values, we won't get them right or act effectively. Consider how ineffectual appeals to reason are in discussions of gun ownership in the US or fox hunting in the UK-precisely because such appeals fail to recognise the role of these issues as expressive of values relating to identity and belonging. This is not to deny that changing practices can change culture; recall that we claimed that the material-ideal dyad must be part of any viable conception of culture. Changing rules, policies and practices can make a difference, but the case made here is that real change requires us to understand such changes at the material end of the dyad as exemplary and expressive of a shift at the ideal end, in the corresponding system of values.

To conclude: the aims of the critical mathematics education movement require attention to culture, but this requires a conception of culture that avoids the shortcomings of ethnomathematics, and is especially apt to avoid the risks of stereotyping and essentialism. While speaking of 'culture', we must recall that pupils belong to multiple cultures: school culture, peer culture, home culture, and so on (this may be what Presmeg's first principle was trying to capture). These all interact in unpredictable ways, and pupils all have their own ways of relating to the cultural groups that they find themselves in. Recall our observation that 'culture' sometimes functions as a mass-noun rather than as a count-noun. The cultural life of a pupil may be more like the turbulent flow of liquids than a stable relation to a static object. Since culture is an unavoidable topic given the aims of the critical mathematics education movement, we need a notion of culture that captures this dynamism. We believe that the two-dimensional framework offered here (the two dimensions being material/ideal and normative/descriptive) may be a useful contribution to this endeavour.

\section{References}

Alrø, Helle, Ravn, Ole \& Valero, Paola (eds.) (2010) Critical Mathematics Education: Past, Present and Future. Festschrift for Ole Skovsmose. Rotterdam: Sense Publisher.

Banks, J.A., Banks, \& McGee, C. A. (1989). Multicultural education. Needham Heights, MA: Allyn \& Bacon.

Bishop, Alan J. (2008) Values in mathematics and sciences education: Similarities and differences. The Montana Mathematics Enthusiast, 5, 47-58.

Bishop, Alan J. (2016) What would the mathematics curriculum look like if instead of concepts and techniques, values were the focus? In B. Larvor (ed.) Mathematical cultures (pp. 181-188) Switzerland: Springer.

Bourdieu, Pierre (1996) The state nobility: Elite schools in the field of power. Cambridge UK: Polity.

Burton, Leone (ed.) (2010) Which Way Social Justice in Mathematics Education? Westport, CT: Praeger Publishers

D'Ambrosio, U. (1985) Ethnomathematics and Its Place in the History and Pedagogy of Mathematics. For the Learning of Mathematics, 5(1), 44-48.

D'Ambrosio, Ubiratan (2016) Ethnomathematics. A response to the changing role of mathematics in society. In P. Ernest \& B. Sriraman (eds.). Critical Mathematics Education: Theory, Praxis, and Reality (pp. 23-34). Charlotte, North Carolina, USA: Information Age Publishing. 
Doyle, Randi A. \& Voyer, Daniel (2016) Stereotype manipulation effects on math and spatial test performance: A meta-analysis Learning and Individual Differences 47:103-116

Ernest, Paul (2000) 'Why Teach Mathematics?' in White, J. \& Bramall, S. (eds.) (2000) Why Learn Maths? London: London University Institute of Education.

Ernest, Paul (2016) Mathematics and values. In B. Larvor (ed.) Mathematical cultures (pp. 189-214) Switzerland: Springer.

Fink, Thomas \& Mao, Yong (2001) The 85 ways to tie a tie: the science and aesthetics of tie knots Fourth Estate.

François, Karen (2016) Ethnomathematics as a Human Right. In P. Ernest \& B. Sriraman (Eds.). Critical Mathematics Education: Theory, Praxis, and Reality (pp. 193-203). Charlotte, North Carolina, USA: Information Age Publishing.

Gray, Jeremy (2008) Plato's Ghost: The Modernist Transformation of Mathematics. Princeton University Press.

Hopkins, Brian \& Wilson, Robin J. (2004) The truth about Königsberg The College Mathematics Journal 35(3), 198-207

Knijnik, Gelsa (2012) Differentially positioned language games: ethnomathematics from a philosophical perspective Educational Studies in Mathematics 80 (1-2) 87-100

Kroeber, A.L., \& Kluckhohn, C. (1952) Culture: A critical review of concepts and definitions. Harvard University Peabody Museum of American Archeology and Ethnology Papers 47.

Larvor, Brendan (2016a) "What are Cultures?" in Cultures of Mathematics and Logic Selected papers from the conference in Guangzhou, China, 9-12 November 2012. Shier Ju, Benedikt Löwe, Thomas Müller, Yun Xie (eds.) Birkhäuser, Basel

Larvor, Brendan (2016b) Mathematical Cultures: The London Meetings 2012-2014 Edited collection, Birkhäuser, Basel.

Lautman, A. (2006) Les mathématiques, les idées et le réel physique. Vrin, Paris. Introduction and biography by Jacques Lautman; introductory essay by Fernando Zalamea; preface to the 1977 edition by Jean Dieudonné.

Lockhart, Paul (2009) Mathematician's Lament Bellevue Literary Press.

Pais, Alexandre (2010) Criticisms and contradictions of ethnomathematics Educational studies in mathematics, 76(2), 209-230.

Pinxten, Rik \& François, Karen (2011). Politics in an Indian canyon? Some thoughts on the implications of ethnomathematics. Educational Studies in Mathematics, 78(2), 261-273.

Presmeg, Norma C. (1998) Ethnomathematics in Teacher Education Journal of Mathematics Teacher Education 1: 317-339

Skovsmose, Ole (2005) Travelling Through Education. Uncertainty, Mathematics, Responsibility. Rotterdam: Sense Publisher.

Skovsmose, Ole (2014) Critique as uncertainty. Rotterdam: Sense Publisher.

Skovsmose, Ole. (2011) An Invitation to Critical Mathematics Education. Sense Publishers.

Skovsmose, Ole. (2015). (Etno)matemática como discurso. Bolema: Boletim de Educação Matemática, 29(51), 18-37. https://dx.doi.org/10.1590/1980-4415v29n51a02 retreived March 12.

Steen, L. A. (1990). On the shoulders of giants: New approaches to numeracy. Washington, DC: National Academy Press.

Thomas, R. S. D. (1996). Proto-mathematics and/or real mathematics. For the Learning of Mathematics, 16(2), 11-18.

Vithal, Renuka \& Skovsmose, Ole (1997) The End of Innocence: A Critique of Ethnomathematics. Educational Studies in Mathematics. 34(2), 131-157. 